\title{
Curcumin, a natural isolate from Curcuma longa (turmeric) with high $\beta$-hematin inhibitory potential
}

\begin{abstract}
Natural curcuminod isolates from turmeric Curcuma longa that belongs to ginger family Zingiberaceae were collected using reversed phase preparative HPLC coupled to photodiode array detector and their in-vitro effect on $\beta$-hematin inhibition were explored. Turmeric ethanolic crude extract was ten-fold less active in comparison to chloroquine positive control. Moreover, semi-quantitative and quantitative analysis results revealed that curcumin analytical standard, and to a lesser extent, the turmeric three natural isolates impeded $\beta$-hematin formation in a relatively comparable extent to chloroquine and amodiaquine positive controls. This result unequivocally indicates the key role curcumin active ingredient plays as an inhibitor of $\beta$-hematin formation. Edible turmeric root powder is commercially available and safe to use.
\end{abstract}

Keywords: curcumin, prep-HPLC, curcuma longa, antimalaria, $\beta$-hematin, chloroquine
Volume 7 Issue I - 2019

\author{
Saleh Abu-Lafi,' Mutaz Akkawi, ${ }^{2}$ Qassem \\ Abu-Remeleh, ${ }^{2}$ Mutaz Qutob, ${ }^{3}$ Pierre \\ Lutgen ${ }^{4}$ \\ 'Faculty of Pharmacy, Al-Quds University, Palestine \\ ${ }^{2}$ Life Sciences Department, College of Science and Technology, \\ Al-Quds University, Palestine \\ ${ }^{3}$ Department of Earth and Environmental Sciences, College of \\ Science and Technology, Al-Quds University, Palestine \\ ${ }^{4}$ IFBV-BELHERB, Luxembourg
}

Correspondence: Mutaz Akkawi, Life Sciences Department, College of Science and Technology, Al-Quds University, Abu-Dis, Palestine, Tel ++972(0)526435785, Fax ++ 972-2-6260903, Email akkawi74@gmail.com

Received: January 19, 2019 | Published: February 12, 2019

\section{Introduction}

Malaria is a mosquito borne parasitic disease of the blood caused by a Protozoan belonging to the genus Plasmodium. It is considered the most prevalent infectious disease in the world. According to the World Health Organization and the World Malaria Report of 2018 , there were an estimated 219 million cases of malaria and 435000 related deaths in 2017, compared with 217 million cases in 2016 which highlight the need for a new effective drugs against malaria. ${ }^{1}$ Malaria is caused by different species of Plasmodium, of which P. falciparum is the most virulent human malaria parasite, contributing to $90 \%$ of total malarial deaths. ${ }^{2,3}$ The life cycle of Plasmodium species is complex. During the intra-erythrocytic stage, the Plasmodium feeds on the hemoglobin of the hosts RBC's. ${ }^{4}$ Active metabolism of hemoglobin takes place in an acidic lysosome-like organelle called the food vacuole that has a $\mathrm{pH}$ of about 5.0 to $5.4 .^{5-8}$ Large amounts of free heme known as ferriprotoporphyrin (IX) (FePPIX) are released. ${ }^{9,10}$ The accumulation of ferriprotoporphyrin (IX) causes the generation of reactive oxygen species which may induce oxidative stress leading to parasitic death. ${ }^{11}$ However, plasmodium parasite acquired a unique detoxification method of free heme through its conversion into a non-toxic, inert, insoluble, crystalline and black-brown pigment called hemozoin. ${ }^{12}$

$\beta$-Hematin crystals (hemazoin) are made of dimer of hematin molecules that are oxygen coordinate bond links the central iron of one hematin to the oxygen of the carboxylate side-chain of the adjacent hematin. ${ }^{13}$ Many clinically used antimalarial drugs such as chloroquine and amodaquine are thought to act by inhibiting the formation of hemozoin in the food vacuole. This prevents the detoxification of the heme released in this compartment, and kills the parasite. ${ }^{14}$ Through the years, quinoline-ring based drugs such as chloroquine have proved their effectiveness as antimalarial drugs by accumulating inside the food vacuoles of the parasite preventing the formation of hemozoin, killing the parasite ${ }^{15,16}$ Recently strains of plasmodium falciparum formed resistance to Chloroquine, drawing attention to discover novel antimalarial candidates. Curcuma longa (turmeric) has a long history of use to treat inflammatory conditions. ${ }^{17}$ It is the major source of the active polyphenol, curcumin. Extensive research over the past half century has displayed that curcumin can modulate multiple cell signaling pathways..$^{18,19}$ More recently, the in vivo antiplasmodial activity of curcuminoids was evaluated. ${ }^{20}$ This research, however, aimed to explore the inhibitory effect of different natural curcuminod isolates including curcumin analytical standard on $\beta$-hematin using semi-quantitative and quantitative screening methods.

\section{Materials and methods}

HPLC grade solvents of acetonitrile $(\mathrm{ACN})$ and water $\left(\mathrm{H}_{2} \mathrm{O}\right)$, dimethyl sulfoxide (DMSO), chloroquine diphosphate salt (CQ), amodiaquine hydrochloride (AD), curcumin analytical standard $(98 \%$ by HPLC), sodium acetate, and hemin chloride were all purchased from Sigma-Aldrich. Ethanol (EtOH) was from Merck (Germany), and glacial acetic acid was from Fluka. Organic ground turmeric root powder (Bonomolli, Italy) was bought from a local market in Jerusalem.

\section{Preparation of turmeric extract}

Two grams of fine-powdered organic ground turmeric was soaked in $150 \mathrm{ml}$ of absolute ethanol $99.5 \%$, left for about $24 \mathrm{~h}$ at room temperature and then filtered using MN $615 . \varnothing 110 \mathrm{~mm}$ filter paper. The resultant extract was evaporated using (IKA WEREK RV06-ML) rotary evaporator at $55-60^{\circ} \mathrm{C}$ under reduced pressure. Then, it was lyophilized using Labconco freeze drier (USA), until constant weight was achieved. The final dried extract was stored in an amber bottle and kept in the fridge.

\section{Semi-quantitative in-vitro Method}

According to Deharo assay, ${ }^{21}$ a mixture containing of $50 \mu \mathrm{L}$ of $0.5 \mathrm{mg} / \mathrm{ml}$ hemin chloride freshly dissolved in dimethyl sulphoxide (DMSO), $100 \mu \mathrm{L}$ of $0.5 \mathrm{M}$ sodium acetate buffer $(\mathrm{pH} 4.4)$, and $50 \mu \mathrm{L}$ 
of the tested potential anti-malarial drug solution or control, was incubated in a normal non-sterile 96 -well flat bottom plate at $37^{\circ} \mathrm{C}$ for $18-24 \mathrm{~h}$. It is important that the solutions be added to the plate in this order. The plate was then centrifuged for 10 minutes at 4000rpm. The supernatant was removed and the $\mathrm{pH}$ of reaction was measured. The final $\mathrm{pH}$ of the mixture should be between (5.0-5.2). The wells were washed with $200 \mu \mathrm{LMSO}$ per well to remove free hemin chloride. The plate was centrifuged again, discharging the supernatant afterwards. The $\beta$-hematin remaining was then dissolved in $200 \mu \mathrm{l}$ of $0.1 \mathrm{M} \mathrm{NaOH}$ to form an FP that can be measured spectrophotometrically. Finally the absorbance was read at $405 \mathrm{~nm}$ using ELISA reader.

\section{Quantitative method}

According to Blauer \& Akkawi ${ }^{22}$ method, a freshly prepared stock solution of hemin chloride was prepared by dissolving the salt in dimethyl sulfoxide and incubated for 30 minutes at $30^{\circ} \mathrm{C}$; stock solution of curcumin dissolved in $0.02 \mathrm{~N} \mathrm{NaOH}$ prepared. A 0.5 $\mathrm{M}$ of sodium acetate buffer ( $\mathrm{pH} 4.4$ ) was also prepared. The final concentration of hemin and the complex in the reaction were 0.2 and $0.4 \mathrm{mM}$ respectively. The whole mixture was left for $18-24 \mathrm{~h}$ at $37^{\circ} \mathrm{C}$ without stirring. The total volume of the reaction mixture was $32 \mathrm{~mL}$, and the final $\mathrm{pH}$ was 4.9-5.2.Samples were centrifuged for 10 min using a serological (JouanB4) centrifuge. The supernatant was discarded and the precipitate was washed with ultrapure water and quantitatively transferred to a Millipore Swinnex 13 filter containing Whatman filter paper No. 50, already lyophilized to a constant weight in freeze-drying machine (Labconco Freezone). DMSO was passed slowly through the filter until the filtrate remained feebly colored and washed again with ultra-pure water. The remaining was then lyophilized to a constant weight.

\section{Chromatographic conditions}

Fresh 400mg turmeric extract was dissolved with $40 \mathrm{ml}$ of (EtOH: $\mathrm{H}_{2} \mathrm{O} ; 3: 1 ; \mathrm{V}: \mathrm{V}$ ), giving rise to a very clear orange solution. Filtration through $0.46 \mu \mathrm{m}$ PTFE disposable membrane brings about a solution of $10 \mathrm{mg} / \mathrm{ml}$ concentration. Small concentration was chosen to permit base-line separation of the structurally related turmeric compounds and therefore to collect pure isolates. One $\mathrm{ml}$ $(1000 \mu \mathrm{l})$ was injected at flow of $20 \mathrm{ml} / \mathrm{min}$ using gradient mixture of acetonitrile ACN and $\mathrm{H}_{2} \mathrm{O}$. First, a $45 \%$ of ACN was chosen and then raised linearly to $70 \%$ in 13 minutes. The percentage increased then to $100 \%$ in one minute and hold constant for 5 minutes to clean the column. Finally, the percentage was decreased back to $45 \%$ ACN in one minute. The column equilibration time was set for 5 minutes before injection new sample.

\section{Results and discussion}

\section{Preparative HPLC of turmeric extract}

Turmeric extract contains major three curcuminoids, namely, bisdemethoxycurcumin (a), demethoxycurcumin (b) and curcumin (c) which is responsible for its yellow color (Figure 1). These curcuminoids are structurally related; therefore, their separation with satisfactory resolution is considered a challenge. The polarity order of the compounds is as follows: (a) $>$ (b) $>$ (c). Consequently, as expected, (a) eluted first while (c) eluted last in reversed phase chromatography mode. Figure 2 and Figure 3 shows the preparative chromatographic peaks profile of the major three close-by eluted curcuminoids and turmerones at wavelengths of 425 and $245 \mathrm{~nm}$ respectively. The overlaid UV-VIS spectra from 200-600nm using the photodiode array detector are seen in the same figures.

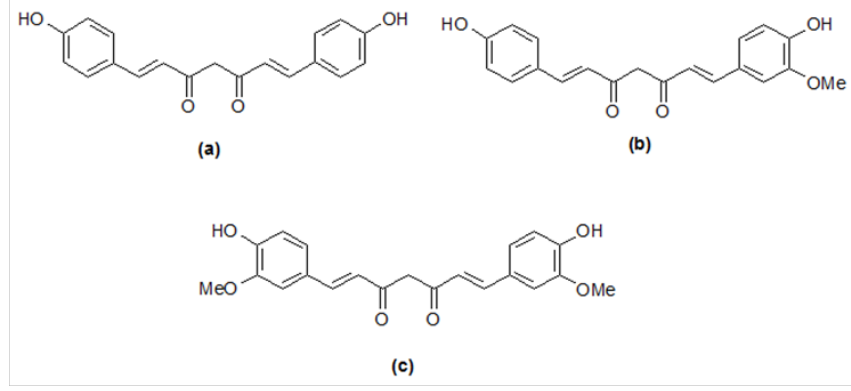

Figure I Chemical structures of the main curcuminoids in ethanolic extract, bisdemethoxycurcumin (a), demethoxycurcumin (b) and curcumin (c).

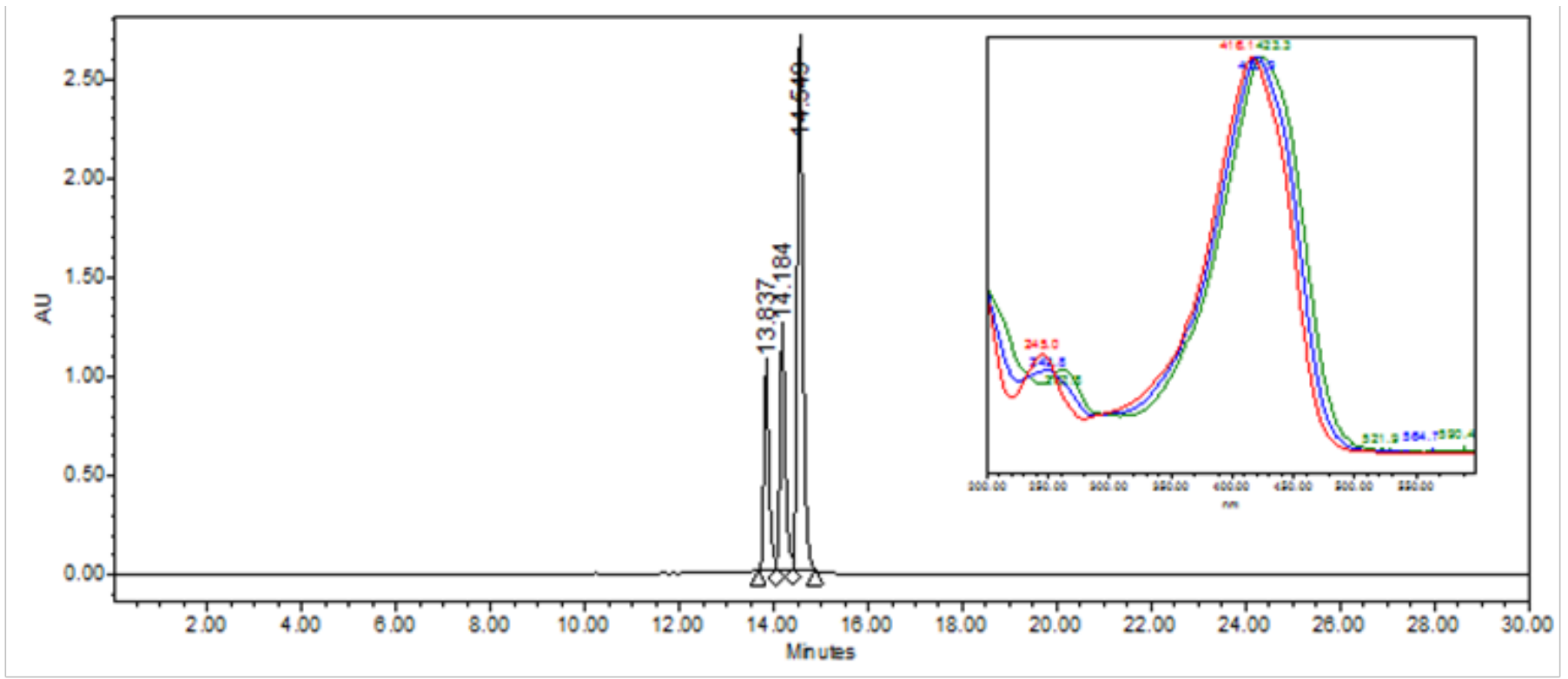

Figure 2 Preparative HPLC-PDA chromatogram of crude curcumin dissolved in 100\% ethanol at $420 \mathrm{~nm}$. 


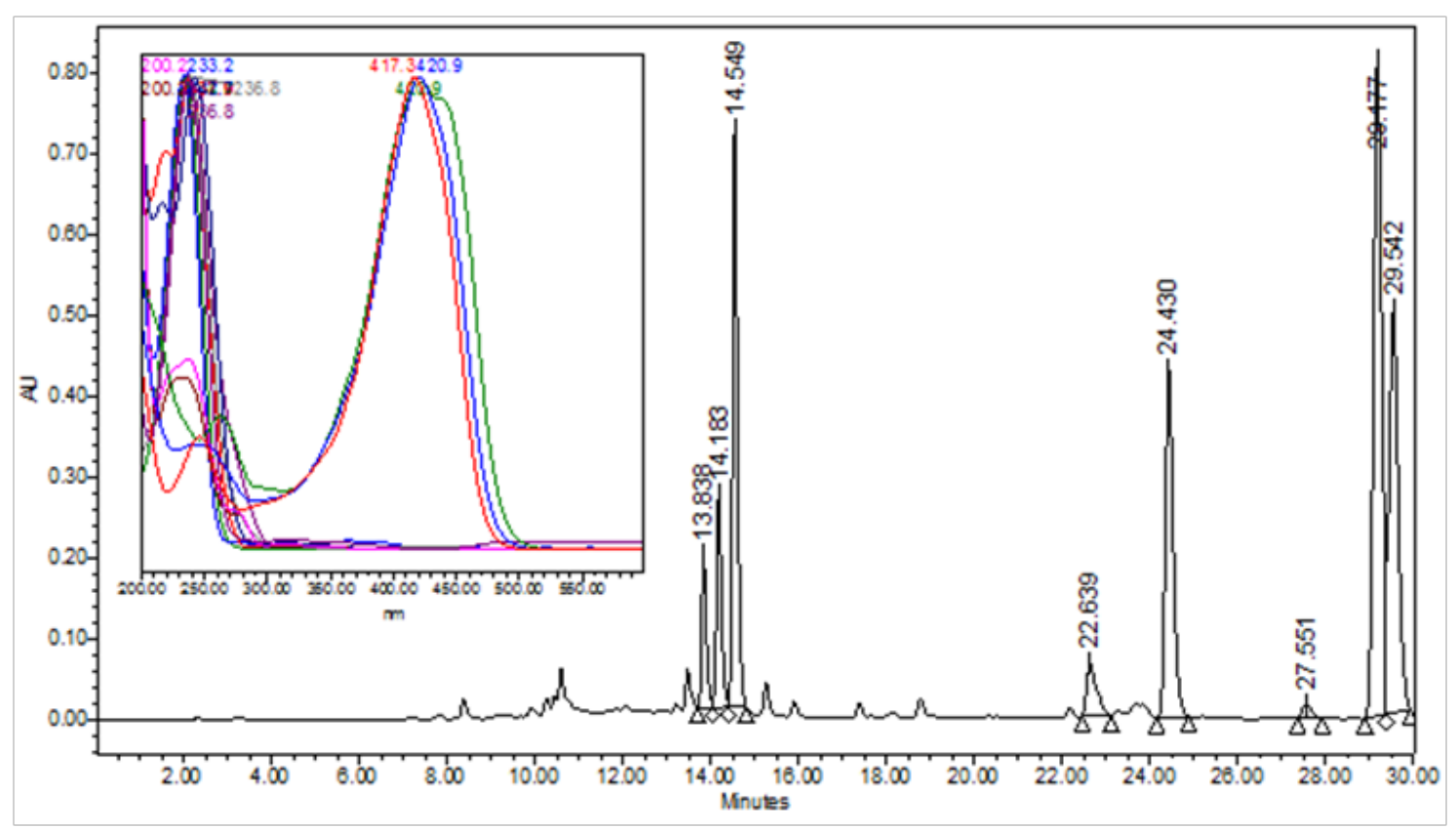

Figure 3 Preparative HPLC-PDA chromatogram of crude curcumin dissolved in 100\% ethanol at $240 \mathrm{~nm}$.

Phytochemical curcuminoid (a), which eluted first, showed maximum adsorption at $416.1 \mathrm{~nm}$ (red, retention of 13.83 minutes), while (b) exhibited maximum absorption at $420.9 \mathrm{~nm}$ (blue, retention of 14.18 minutes) while curcuminoid (c) showed maximum absorption at $423.3 \mathrm{~nm}$ (green, retention of 14.54 minutes). Satisfactory resolution between the three compounds were enabled us to isolate relatively pure isolates of each compound. As seen in Figure 3, turmerones eluted at longer retention time and monitored at a wavelength of $240 \mathrm{~nm}$. According to their UV spectrum and mass spectrometric data, most probably, the ar-turmerone, $\alpha$ and $\beta$-tumerone eluted at 24.43 , 29.17 and 29.54 minutes respectively. ${ }^{23}$

\section{Semi-quantitative method}

Results of the in-vitro semi-quantitative experiments on pure curcumin analytical standard and crude turmeric extract along with individual isolates of curcuminoid (designated as F1, F2 and F3) are depicted in Figure 4 and Figure 5 respectively. The antimalarial efficiency was evaluated from the absorption of $\beta$-haematin at $405 \mathrm{~nm}$ of the turmeric ethanolic extract in comparison to water and $\mathrm{NaOH}$ negative control and chloroquine positive control (CQ- $0.1 \mathrm{mg} / \mathrm{ml}$ ). Absorption is inversely proportional to extract efficiency and to hemozoin content. As in Figure 4, pure curcumin analytical standard showed high activity as revealed from its absorption value $(0.146$ at $0.1 \mathrm{mg} / \mathrm{ml})$ in comparison to $(0.107$ at $0.1 \mathrm{mg} / \mathrm{ml})$ value of the CQ positive control. When the concentration of curcumin standard increased five folds $(0.5 \mathrm{mg} / \mathrm{ml})$, the antimalarial activity increased low below the chloroquine positive control.

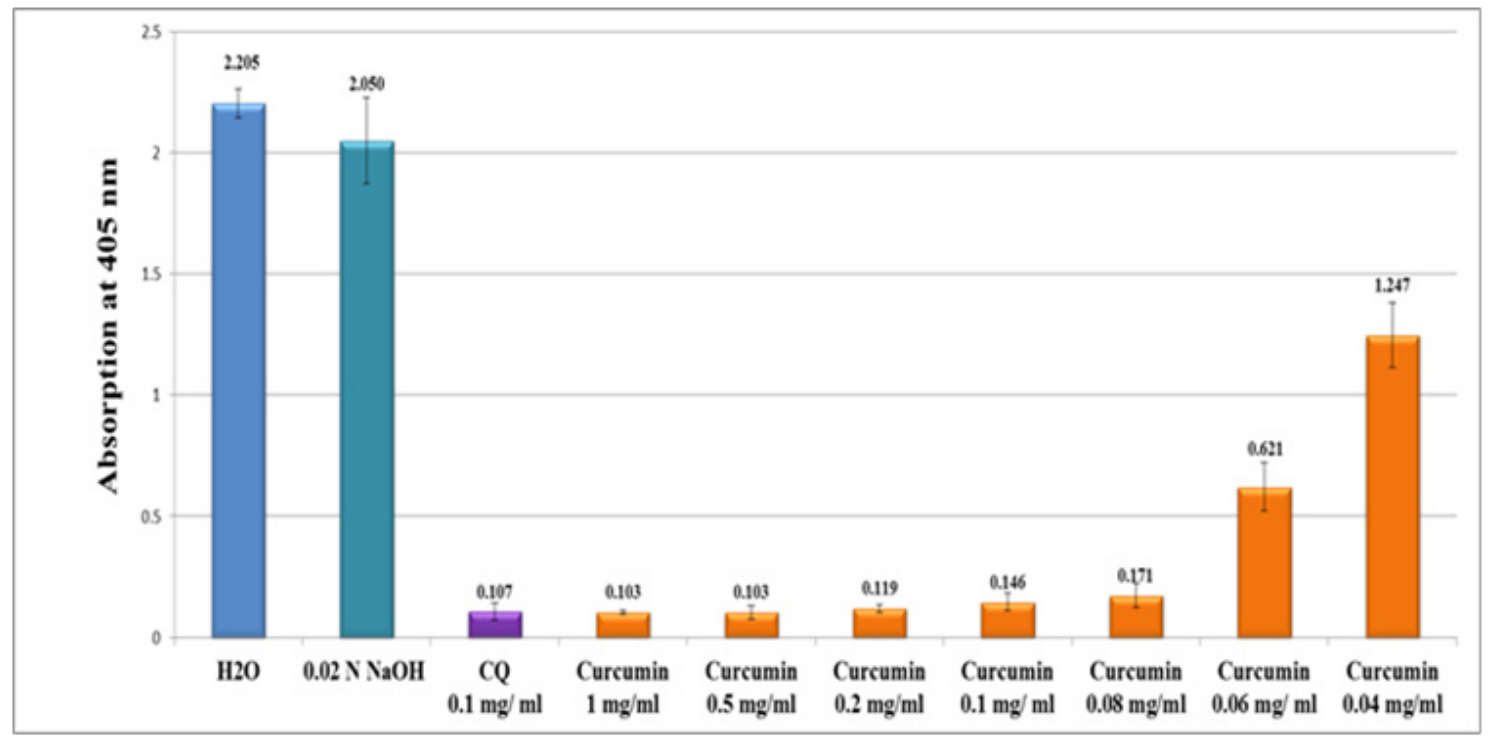

Figure 4 Column diagram representing the efficacy of curcumin analytical standard dissolved in $0.02 \mathrm{~N} \mathrm{NaOH}$ compared to water and $0.02 \mathrm{~N} \mathrm{NaOH}$ solution negative controls and chloroquine (CQ- $0.1 \mathrm{mg} / \mathrm{ml}$ ) positive control, showing the absorption values of dissolved $\beta$-hematin (alkaline hematin) at $405 \mathrm{~nm}$ using ELISA reader. Each result represents the average of 16 individual experiments. 


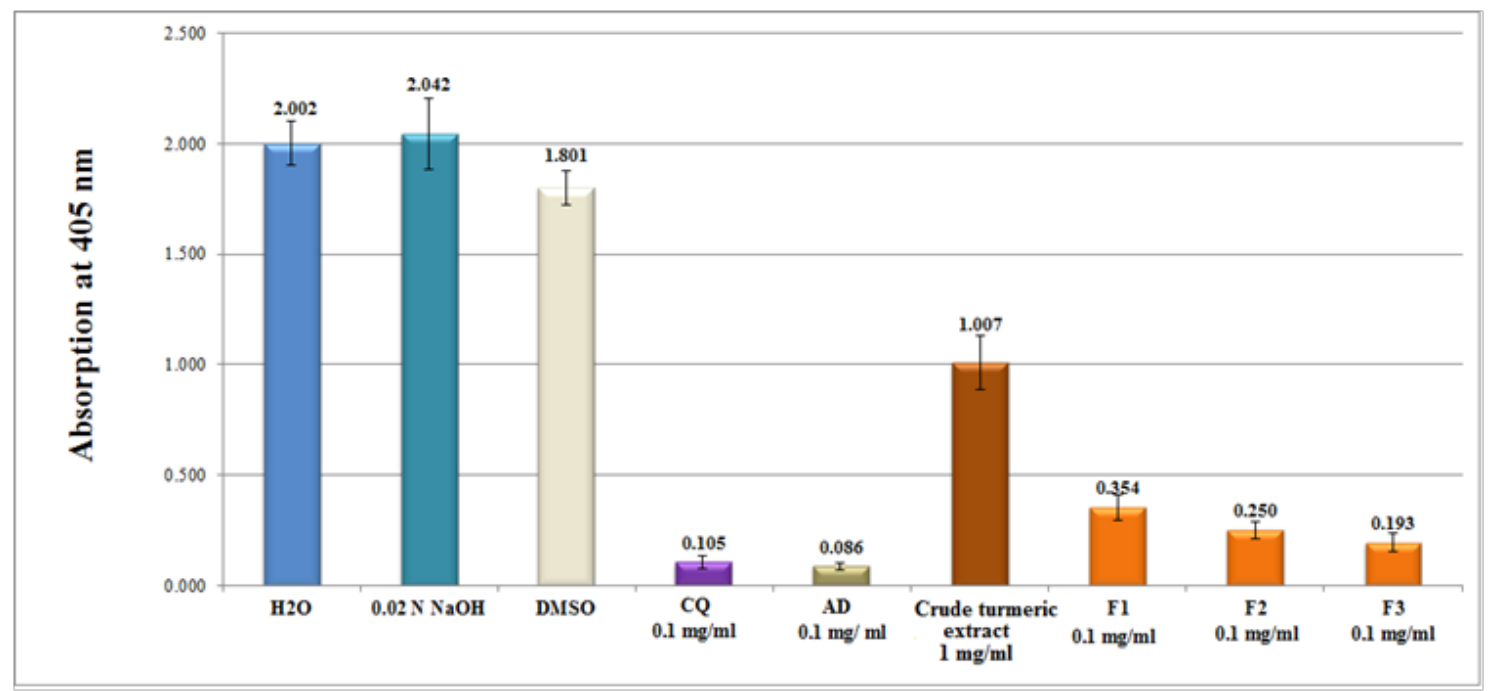

Figure 5 Column diagram representing the efficacy of $\beta$-hematin inhibition of crude turmeric extract (dissolved in DMSO) and curcuminoid pure isolate fractions, (FI Bisdemethoxycurcumin of $0.1 \mathrm{mg} / \mathrm{ml}$ ), ( $\mathrm{F} 2$ demethoxycurcumin of $0.1 \mathrm{mg} / \mathrm{ml}$ ) and ( $\mathrm{F} 3 \mathrm{Curcumin}, 0.1 \mathrm{mg} / \mathrm{ml}) \mathrm{dissolved}$ in $0.02 \mathrm{~N} \mathrm{NaOH}$ compared to chloroquine (CQ), amodiaquine (AD) positive controls $(0.1 \mathrm{mg} / \mathrm{ml})$, while water and DMSO were used as negative controls. Each result represents an average of 16 individual experiments.

When a crude turmeric extract was examined, the activity decreased 10 fold compared to positive controls of chloroquine and amodiaquine. In the contrary, relatively pure isolates gave adequate inhibitory results in the following order: $\mathrm{F} 3>\mathrm{F} 2>\mathrm{F} 1$ (Figure 5). The structural features of the three isolates demonstrate that the addition of methyl ether linkage increased activity and therefore played a key role on the inhibition of $\beta$-haematin (Figure 1). Comparing analytical curcumin standard activity with $\mathrm{F} 1$ isolate showed small difference in favor of curcumin standard. The difference most probably attributed to the purity of F1 (92\%) compared to curcumin standard (98\%).

\section{Quantitative method}

The result of curcumin analytical standard compared to DMSO negative control and amodiaquine positive control in terms of $\beta$-hematin formation is depicted in Figure 6 while comparison in terms of drug efficiency is seen in Figure 7. As shown in Figure 6, the percentage yield of $\beta$-hematin formation in the presence of curcumin analytical standard and AQ positive control was $21.2 \%$ and $8.2 \%$ respectively. Both active compounds were at concentration $0.4 \mathrm{mM}$ comparing to the negative control which was $89.3 \%$. Comparison in terms of efficiency of curcumin versus $\mathrm{AD}$ positive control is shown in Figure 7. Curcumin showed considerable inhibitory effect on $\beta$-hematin formation with efficiency of $78.8 \%$ compared $91.8 \%$ of AQ and $10.7 \%$ for inactive DMSO solvent. Assuming curcuminoid isolates act via similar mechanism to chloroquine, to which a complex between chloroquine and ferriheme led to the formation of a complex which prevent $\beta$-hematin formation. Similarly, the interaction of ferriheme with curcumin most likely formed by the interaction of $\mathrm{Fe}^{\mathrm{III}}$ metal center with one of the carbonyl group of the curcumin. Moreover, the side chain carboxyl group of heme may interact with one the hydroxyl groups of curcumin. ${ }^{24,25}$

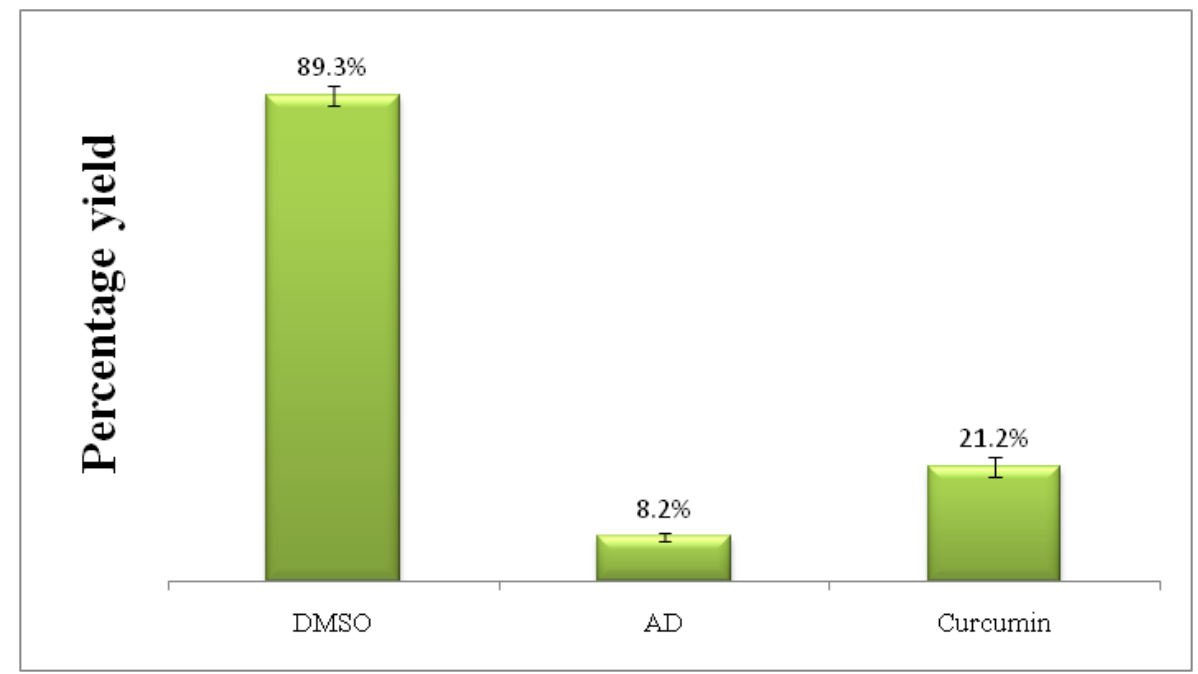

Figure 6 Column diagram representing the percentage yields of curcumin compared to amodiaquine (AD) and DMSO at $0.4 \mathrm{mM}$. Yields are inversely proportional to drugs efficiency, the lower the percentage yield, the better the activity. 


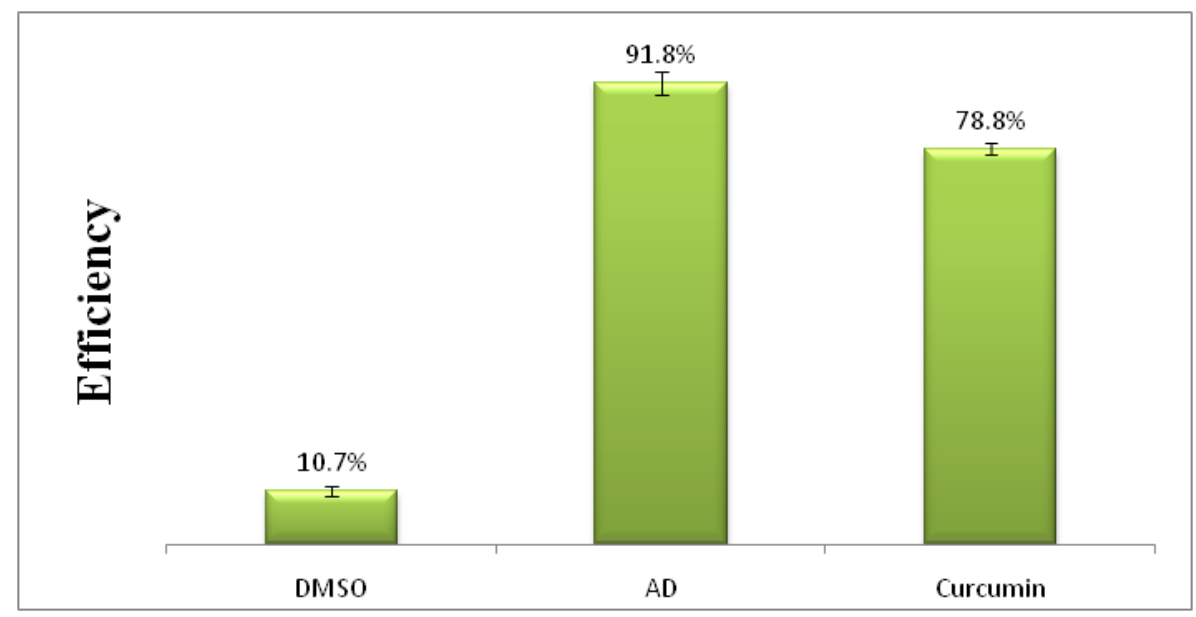

Figure 7 Column diagram representing the efficiency of curcumin compared to amodiaquine (AD) and water at a concentration of 0.4 mM.

\section{Conclusion}

Pure isolates from turmeric powder showed promising antimalarial activity compared to chloroquine drug in-vitro. Turmeric root powder is safe and affordable to everyone besides being used in food recipes. Curcumin is a promising active ingredient that does not have the disadvantage resistance to malarial paradise as in chloroquine drug.

\section{Acknowledgments}

We are grateful for Prof. Mohammad Abul Haj for his helpful discussions and insightful comments.

\section{Conflicts of interest}

The authors declare that there is no conflict of interest.

\section{References}

1. World Malaria Report. Luxembourg: World Health Organization; 2018 $210 \mathrm{p}$.

2. Rathore D. Strategies for Malaria Control. VBI Scientific Annual Report; 2006. 49-53 p

3. Weissbuch I, Leiserowitz L. Interplay between malaria, crystalline hemozoin formation, and antimalarial drug action and design. Chem Rev. 2008;108(11):4899-4914.

4. Francis SE, Sullivan DJ, Goldberg DE. Haemoglobin metabolism in the malaria parasite Plasmodium falciparum. Annu Rev Microbiol. 1997;51:97-123.

5. Liu J, Gluzman I, Drew ME, et al. The role of Plasmodium falciparum food vacuole plasmepsins. J Biol Chem. 2005;280(2):1432-1437.

6. Banerjee R, Liu J, Beatty W, et al. Four plasmepsins are active in the Plasmodium falciparum food vacuole, including a protease with an active-site histidine. Proc Natl Acad Sci USA. 2002;99(2):990-995.

7. Rosenthal PJ. Cysteine proteases of malaria parasites. Int J Parasitol. 2004;34(13-14):1489-1499.

8. Spiller DG, Bray PG, Hughes RH, et al. The $\mathrm{pH}$ of the Plasmodium falciparum digestive vacuole: holy grail or dead-end trail? Trends Parasitol. 2002;18(10):441-444.

9. Müller S. Redox and antioxidant systems of the malaria parasite Plasmodium falciparum. Mol Microbiol. 2004;53(5):1291-1305.

10. Blauer G, Akkawi M. On the preparation of beta-haematin. Biochem J. 2000;346(2):249-250.
11. Kumar S, Guha M, Choubey V, et al. Antimalarial drugs inhibiting hemozoin (beta-hematin) formation: a mechanistic update. Life Sci. 2007;80(9):813-828.

12. Pagola S, Stephens PW, Bohle DS, et al. The structure of malaria pigment beta-haematin. Nature. 2000;404(6775):307-310.

13. Lemberg R, Legge JW. Hematin compounds and bile pigments; their constitution, metabolism, and function. New York: Interscience; 1949.

14. Ziegler J, Linck R, Wright DW. Heme Aggregation inhibitors: antimalarial drugs targeting an essential biomineralization process. Curr Med Chem. 2001;8(2):171-189.

15. Slater GA, Swiggard WJ, Orton BR, et al. An Iron-Carboxylate Bond Links the Heme Units of Malaria Pigments. Proc Natl Acad Sci. 1991;88(2):325-329.

16. Fong KY, Wright DW. Hemozoin and antimalarial drug discovery. Future Med Chem. 2013;5(12):1437-1450.

17. Jurenka JS. Anti-inflammatory properties of curcumin, a major constituent of Curcuma longa: a review of preclinical and clinical research. Altern Med Rev. 2009;14(2):141-153.

18. Hewlings SJ, Kalman DS. Curcumin: A Review of Its' Effects on Human Health. Foods. 2017;6(10):1-11.

19. Gupta SC, Patchva S, Aggarwal BB. Therapeutic Roles of Curcumin: Lessons Learned from Clinical Trials. AAPS J. 2013;15(1):195-218.

20. Busari ZA, Dauda KA, Morenikeji OA, et al. Antiplasmodial activity and toxicological assessment of curcumin PLGA-encapsulated nanoparticles. Front Pharmacol. 2017;8:622.

21. Deharo E, Garcia RN, Oporto P, et al. A non-radiolabelled ferriprotoporphyrin biomineralisation inhibition test for the high throughput screening of antimalarial compounds. Exp Parasitol. 2002;100(4):252-256.

22. Blauer G, Akkawi M. Investigations of B and $\beta$-hematin. $J$ Inorg Biochem. 1997;66(2):145-152.

23. Karioti A, Fani E, Vincieri FF, et al. Analysis and stability of the constituents of Curcuma longa and Harpagophytum procumbens tinctures by HPLC-DAD and HPLC-ESI-MS. Journal of Pharmaceutical and Biomedical Analysis. 2011;55(3):479-486.

24. Bicer N, Yildiz E, Yeganib AA, et al. Synthesis of curcumin complexes with iron(III) and manganese(II), and effects of curcumin-iron(III) on Alzheimer's disease. New J Chem. 2018;42(10):8098-8104.

25. Özbolat G, Yegani AA, Tuli A. Synthesis, characterization and electrochemistry studies of iron(III) complex with curcumin ligand. Clin Exp Pharmacol Physiol. 2018;45(11):1221-1226. 